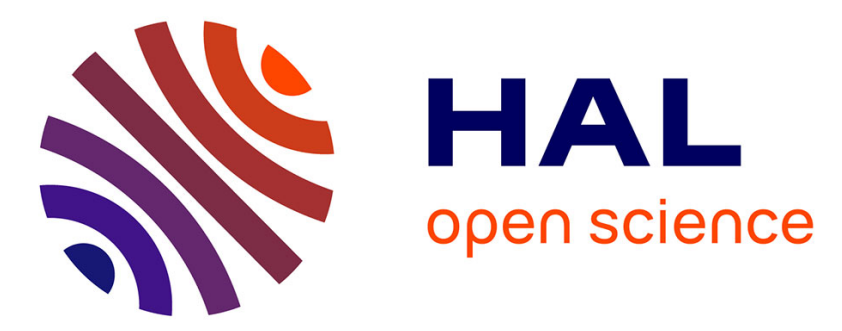

\title{
Superelastic property induced by low-temperature heating of a shape memory $\mathrm{Ti}-24 \mathrm{Nb}-0.5 \mathrm{Si}$ biomedical alloy

\author{
A. Ramalohary, P. Castany, P. Laheurte, F. Prima, T. Gloriant
}

\section{- To cite this version:}

A. Ramalohary, P. Castany, P. Laheurte, F. Prima, T. Gloriant. Superelastic property induced by low-temperature heating of a shape memory Ti-24Nb-0.5Si biomedical alloy. Scripta Materialia, 2014, 88, pp.25-28. 10.1016/j.scriptamat.2014.06.009 . hal-01114428

HAL Id: hal-01114428

https://hal-univ-rennes1.archives-ouvertes.fr/hal-01114428

Submitted on 27 Aug 2018

HAL is a multi-disciplinary open access archive for the deposit and dissemination of scientific research documents, whether they are published or not. The documents may come from teaching and research institutions in France or abroad, or from public or private research centers.
L'archive ouverte pluridisciplinaire HAL, est destinée au dépôt et à la diffusion de documents scientifiques de niveau recherche, publiés ou non, émanant des établissements d'enseignement et de recherche français ou étrangers, des laboratoires publics ou privés. 


\title{
Superelastic property induced by low temperature heating of a shape memory Ti-24Nb-0.5Si biomedical alloy
}

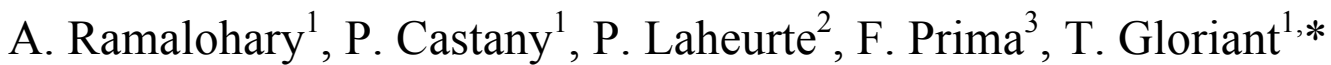 \\ ${ }^{1}$ Institut des Sciences Chimiques de Rennes, UMR CNRS 6226 ISCR, INSA Rennes, 20 Avenue des Buttes \\ de Coësmes, F-35708 Rennes, France \\ ${ }^{2}$ Laboratoire d'Etude des Microstructures et de Mécanique des Matériaux, UMR CNRS 7239 LEM3, Université \\ de Lorraine, Ile de Saucly, F-57045 Metz, France \\ ${ }^{3}$ Laboratoire de Physico-Chimie des Surfaces, UMR CNRS 7045 LPCS, Chimie-ParisTech, ENSCP Paris, rue \\ Pierre et Marie Curie, F-75005 Paris, France \\ *Corresponding author : Thierry.Gloriant@insa-rennes.fr (Prof. T. Gloriant)
}

\begin{abstract}
In this study, we have explored a new way to obtain a superelastic titanium-based alloy. Contrary to the classical method consisting to obtain the $\beta$ microstructure directly by water quenching from the high temperature $\beta$-phase domain, this way consists in obtaining first a shape memory alloy displaying a fully $\alpha$ " martensitic microstructure and then a superelastic behavior after applying a low temperature heating.
\end{abstract}

Keywords: titanium; biomedical alloy; microstructure; martensite transformation; superelasticity.

Alloys possessing shape memory or superelastic behavior are of great interest for biomedical functional devices such as stents, osteosynthesis staples, orthodontic arch wires, etc. The alloys commonly used for such devices belong to the NiTi family (e.g. Nitinol) due to their exceptional shape memory and superelastic properties. However, hypersensitivity and toxicity of nickel remain a problem in many clinical cases and the use of nickel must be avoided [1]. Consequently, nickel-free titanium-based alloys composed only of non-cytotoxic alloying elements such as $\mathrm{Nb}, \mathrm{Ta}, \mathrm{Zr}$ are now widely studied [2-4]. The reason for this interest is due to the fact that, depending to the chemical composition, metastable $\beta$ titanium-based alloys can be mechanically 
unstable. Consequently, they can also exhibit shape memory effect and superelastic behavior. Indeed, a reversible martensite transformation between the parent $\beta$-phase (austenite) and the $\alpha$ "-phase (martensite) formed is observed in such alloys [5-7]. In these alloys, the shape memory effect is obtained when the quenched microstructure is composed of the self-accommodating $\alpha^{\prime \prime}$ martensitic phase (orthorhombic phase) at room temperature. When this self-accommodating martensitic microstructure is mechanically deformed into reoriented $\alpha$ " variants, the shape recovery can be achieved by heating, which induces a reversible martensite transformation into the austenic $\beta$ phase (body-centered cubic phase). Superelastic (or pseudoelastic) behavior is obtained when the quenched microstructure is composed of the $\beta$-metastable phase at room temperature. In this case, a stress-induced martensite transformation ( $\beta$ into $\alpha ")$ can directly occur under mechanical stimulation and large elastic recovery (superelasticity) can be obtained due to the fact that this transformation is fully reversible once the mechanical stress is released. From tensile tests, both shape memory and superelastic effects can be highlighted by the presence of a stress plateau on their tensile curves, and thus present a characteristic double-yielding behavior. However, the stress plateau is the consequence of the reorientation of the $\alpha^{\prime \prime}$ martensitic variants in the case of the shape memory alloy while it is due to the reversible martensite transformation in the case of the superelastic alloy. Numerous works carried out on this kind of alloy have focused on alloys belonging to the binary $\mathrm{Ti}-\mathrm{Nb}$ system. Unfortunately, the superelastic property observed is far less than that of NiTi and does not exceed $2 \%$ of elastic recovery at best $[3,5-7]$. However, it was showed that addition of a third or a fourth element such as Al or Sn improves the elastic recovery and about $3 \%$ of elastic recovery can be reached in some cases $[8,9]$. Furthermore, addition of interstitial alloying elements $(\mathrm{O}, \mathrm{N})$ was also observed to be beneficial to enhance significantly both the superelasticity and the mechanical strength [10-12].

In this study, we have explored a new way to obtain a superelastic alloy. Unlike the classical method, which consists of obtaining the $\beta$ microstructure directly by water quenching from the high-temperature $\beta$-phase domain, this method consists of obtaining first a shape memory alloy displaying a fully $\alpha$ " martensitic microstructure and then a superelastic behavior after applying a low-temperature heating. This new method has been validated with $\mathrm{Ti}-24 \mathrm{Nb}-0.5 \mathrm{Si}$ alloy.

The Ti-24Nb-0.5Si (at.\%) alloy was synthesized by cold crucible levitation melting under a pure argon atmosphere by using high-purity raw elements of titanium (99.999\%), niobium (99.99\%) and silicon (99.99\%). The obtained ingot was then homogenized at $1223 \mathrm{~K}$ for $72 \mathrm{ks}$ under high vacuum $\left(10^{-7} \mathrm{mbar}\right)$, quenched in water (at room temperature) and cold rolled until $90 \%$ of reduction in thickness. Samples for 
microstructural analyses and tensile tests were machined from this cold-rolled sheet. Tensile samples were machined to obtain normalized shapes: $3 \mathrm{~mm}$ width, $0.5 \mathrm{~mm}$ in thickness and a gage length of $15 \mathrm{~mm}$. All samples were finally solution-treated in the high-temperature $\beta$-phase domain at $1123 \mathrm{~K}$ for $1.8 \mathrm{ks}$ under high vacuum in order to restore a fully recrystallized microstructure from the cold-rolled state, and then water quenched at room temperature.

In this work, microstructures were characterized and observed by X-ray diffraction (Philips, XRD), optical microscopy (Leica, OM) and transmission electron microscopy (JEOL 2100, TEM). XRD analyses were conducted with $\mathrm{Cu} \mathrm{K}_{\mathrm{a}}$ radiation $(\lambda=0.15406$ $\mathrm{nm})$. For the OM observations, samples were mechanically mirror" polished and etched in a $5 \% \mathrm{HF}, 5 \% \mathrm{HNO}_{3}, 90 \% \mathrm{H}_{2} \mathrm{O}$ solution. TEM samples were thinned down with a twin-jet electropolishing system using a $4 \%$ perchloric acid solution in methanol.

Tensile tests were carried out at room temperature (Instron machine, strain rate: $10^{-4} \mathrm{~s}^{-}$ $\left.{ }^{1}\right)$. All tensile tests were performed with the tensile direction parallel to the rolling direction. In this study, cyclic tensile tests consisting of applying $0.5 \%$ strain increments (each followed by a stress release) were specifically carried out in order to characterize the stress plateau, which is related to the superelastic or the shape memory property. An extensometer was used to precisely measure the deformation of the samples.

Dynamic mechanical analysis (DMA) was performed with a Metravib DMA50 operating in static mode to evaluate the characteristic temperatures (austenite start, $\mathrm{A}_{\mathrm{s}}$, and austenite finish, $\mathrm{A}_{\mathrm{f}}$ ) associated with the shape memory effect. Thus, the length variation associated with the strain recovery of a predeformed tensile sample was followed during a heating/cooling cycle (heating and cooling rate of $5 \mathrm{~K} \mathrm{~min}^{-1}$ ) between room temperature and $473 \mathrm{~K}$.

Figure 1 displays a typical XRD profile (Fig. 1a) and optical micrograph (Fig. 1b) of the solution-treated and quenched $\mathrm{Ti}-24 \mathrm{Nb}-0.5 \mathrm{Si}$ alloy microstructure. XRD peaks were all indexed as belonging to the orthorhombic $\alpha$ " phase (space group: $\mathrm{Cmcm}$ ) without the presence of any $\beta$ peak. The cell parameters of this orthorhombic $\alpha$ " phase were found to be: $\mathrm{a}_{\mathrm{a}^{\prime \prime}}=0.318 \mathrm{~nm}, \mathrm{~b}_{\mathrm{a}^{\prime \prime}}=0.478 \mathrm{~nm}$ and $\mathrm{c}_{\mathrm{a}^{\prime \prime}}=0.463 \mathrm{~nm}$. Observations by OM reveal the presence of thin needles inside equiaxed grains, which corresponds to the typical self-accommodating $\alpha^{\prime \prime}$ microstructure generally observed in this kind of alloy. In fact, the needles correspond to the different martensitic $\alpha$ " variants that were formed during the quench. Therefore, the equiaxed microstructure observed by $\mathrm{OM}$ is the signature of the high-temperature $\beta$ microstructure.

Figure 2 a shows a typical tensile engineering stress-strain curve obtained from the 
solution-treated and quenched $\mathrm{Ti}-24 \mathrm{Nb}-0.5 \mathrm{Si}$ alloy. As shown on the curve, the tensile test was performed in a cyclic manner up to $3 \%$ of strain and then in a conventional manner from $3 \%$ to rupture. This tensile curve reveals the presence of a stress plateau at about $180 \mathrm{MPa}$. As we have shown that the quenched alloy presents a self-accommodating $\alpha$ " martensitic microstructure, this stress plateau is only due to the reorientation of the martensitic variants. In fact, as typically observed in this kind of microstructure, the different $\alpha$ " variants adapt their deformation and some can grow to the detriment of others. This reorientation behavior is not reversible on unloading and it is for this reason that a weak strain recovery, mainly elastic, is obtained. On the other hand, the observation of hysteresis between loading and unloading is due to the reversible movement of twin boundaries occurring in the martensitic microstructure. This phenomenon is referred to as the "rubber-like effect" in shape memory alloys [7]. To characterize the shape memory behavior of this kind of alloy, the $\alpha$ " reoriented martensitic microstructure must be heated to reach the austenitic temperature, which corresponds in fact to the $\beta$ phase transformation temperature. Therefore, a quenched $\mathrm{Ti}-24 \mathrm{Nb}-0.5 \mathrm{Si}$ tensile specimen was preliminarily deformed up to $3 \%$ strain in the tensile machine and then heated in the dynamic mechanical analyzer in order to follow both the strain recovery and the temperature variation. Figure $2 b$ presents the DMA strain-temperature curve for a heating-cooling cycle between room temperature and $473 \mathrm{~K}$ (rate: $5 \mathrm{~K} \mathrm{~min}^{-1}$ ).

It can be observed on the curve that almost all the strain was recovered on heating. The residual difference can be attributed to the fact that the strain measurement was not done with an extensometer during the DMA experiment. The $\beta$-phase transformation is observed to start at $\sim 360 \mathrm{~K}$, which corresponds to the austenitic start temperature, $\mathrm{A}_{\mathrm{s}}$, and the alloy becomes fully $\beta$ from about $400 \mathrm{~K}$, which corresponds to the austenitic finish temperature, $A_{f}$, when all the $\alpha$ " martensitic phase is transformed into the $\beta$ phase. After reaching $473 \mathrm{~K}$, the sample was cooled back to the room temperature. It can be seen that there is no variation on cooling although the martensite transformation ( $\beta$ into $\left.\alpha^{\prime \prime}\right)$ must theoretically occur on cooling. In fact, this transformation gives an $\alpha^{\prime \prime}$ self-accommodating microstructure, which is not sensitive to any significant length variation and thus cannot be detected by this kind of test. To confirm that such a martensite transformation has really occurred on cooling, the microstructure of the alloy after the heating-cooling cycle was characterized by XRD and OM. The corresponding XRD profile and optical micrograph are shown in Figure $3 a$ and $b$, respectively. Surprisingly, the XRD profile reveals that only three diffracted peaks are detected (between $30^{\circ}$ and $80^{\circ}$ ) and all could be perfectly indexed with the $\beta$ phase this time (Fig. 3a). On the other hand, the typical $\alpha$ " thin needles seem not to be present in the optical micrograph where only an equiaxed $\beta$ microstructure is observed 
(Fig. 3b). As it was suggested that the thin needles could be submicrometer in size, the sample was also observed by TEM. Figure $3 \mathrm{c}$ and $\mathrm{d}$ present, respectively, a typical TEM dark-field image and electron diffraction pattern obtained from such alloy after the heat treatment. In fact, the dark-field image reveals the presence of well-dispersed nanometer-scale precipitates but these precipitates correspond to the $\omega$ phase (hexagonal phase) in the present case and not to the $\alpha$ " phase. Indeed, both the darkfield image and electron diffraction pattern exhibit the classical two-phase $\beta+\omega_{\text {iso }}$ microstructure usually obtained by low-temperature annealing of metastable $\beta$ titanium alloys. In fact, the formation of $\omega_{\text {iso }}$ after low-temperature annealing has been reported in a few studies carried out on $\mathrm{Ti}-\mathrm{Nb}$ and $\mathrm{Ti}-\mathrm{Nb}-\mathrm{Sn}$ alloys $[13,14]$. Thus, it can be established that the $\omega_{\text {iso }}$ phase formation occurring on heating prevents the

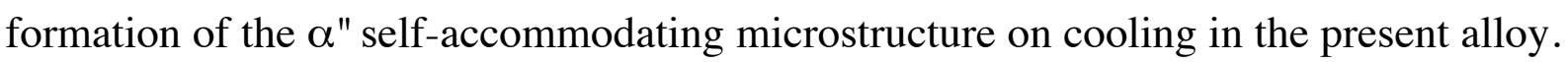
In fact, it has already been reported that the $\omega_{\text {iso }}$ and $\alpha$ " phases behave differently under thermal treatment and that one is formed at the detriment of the other $[15,16]$. This phenomenon can be explained by the fact that the $\beta$-stabilizing elements $(\mathrm{Nb}$ and $\mathrm{Si}$ ) are rejected towards the $\beta$ matrix during the formation of $\omega_{\text {iso }}$ on heating $[17,18]$. Consequently, the martensitic start temperature, $\mathbf{M}_{\mathrm{s}}$, is believed to decrease below room temperature in the present case.

In order to investigate the mechanical behavior of this $\beta+\omega_{\text {iso }}$ microstructure, tensile tests were performed on the $\mathrm{Ti}-24 \mathrm{Nb}-0.5 \mathrm{Si}$ alloy after a low-temperature heating treatment (up to $473 \mathrm{~K}$ ). Figure 4 presents the typical engineering stress-strain curve obtained.

The tensile test was performed in a cyclic manner up to 5\% strain and then in a conventional manner from $5 \%$ to rupture. It can be clearly observed that the alloy presents a superelastic behavior this time. Indeed, the tensile curve exhibits a doubleyielding behavior together with the presence of large hysteresis between loading and unloading, which demonstrates that a stress-induced $\alpha$ " martensite transformation has occurred in the alloy. The superelastic effect is particularly high because, as observed in the enlarged view in Figure 4 and $2.7 \%$ of mechanical strain recovery can be obtained, which is an excellent value compared to others observed with this kind of alloy in a recrystallized $\beta$-state. Thus, it can be concluded that the $\beta+\omega_{\text {iso }}$ microstructure formed after the low-temperature heat treatment possesses the right degree of mechanical instability that permits the reversible stress-induced martensite transformation. Also apparent is the beneficial role of the $\omega_{\text {iso }}$ phase, which does not prevent the stress-induced $\alpha$ " martensite transformation in the present alloy. It should be mentioned that the temperature of heating must be well controlled with this method. Indeed, higher heating temperatures were also used (523 and $573 \mathrm{~K}$ ) in this study but the mechanical behavior was found to be very conventional and without any 
superelastic property. Our hypothesis is that the $\beta$-phase becomes too rich in $\beta$ stabilizer elements and consequently the adequate degree of mechanical instability required is no longer reached. On the other hand, the chemical composition of the alloy is also a very important parameter to control. Indeed, the same experiments were carried out on the binary Ti-24Nb alloy, which also presents a self-accommodating $\alpha$ " microstructure. However, the transformation into a $\beta$ superelastic alloy could not be obtained with this alloy composition. In fact, the temperature of heating necessary to reach the fully $\beta$-phase formation is higher than in the case of the Ti-24Nb-0.5Si alloy $(\sim 52 \mathrm{~K})$ and is immediately accompanied by the formation of an excess of $\omega_{\text {iso }}$-phase, which makes it impossible to obtain a superelastic alloy. This result is corroborated by a recent study carried out on the Ti-24Nb alloy in which the austenite finish temperature was determined to be $477 \mathrm{~K}$ while the $\omega_{\text {iso }}$ phase transformation was found to start at a much lower temperature at $\sim 420 \mathrm{~K}$ by differential scanning calorimetry [13]. In this respect, the addition of Si seems to be very judicious because this element is known to increase the temperature of the $\omega_{\text {iso }}$-phase formation on the one hand, and to decrease the martensitic start transformation, $\mathrm{M}_{\mathrm{S}}$, on the other $[19,20]$ - both conditions fulfilled by the method proposed in the present work.

\section{References}

[1] D.J. Wever, A.G. Veldhuizen, M.M. Sanders, J.M. Schakenraad, J.R. Van Horn, Biomaterials 18 (1997) 1115.

[2] M. Niinomi, Biomaterials 24 (2003) 2673.

[3] S. Miyazaki, H.Y. Kim, H. Hosoda, Mater. Sci. Eng. A 438-440 (2006) 18.

[4] P. Laheurte, F. Prima, A. Eberhardt, T. Gloriant, M. Wary, E. Patoor, J. Mech. Behav. Biomed. Mater. 3 (2010) 565.

[5] H.Y. Kim, Y. Ikehara, J.I. Kim, H. Hosoda, S. Miyazaki, Acta Mater. 54 (2006) 2419.

[6] E. Bertrand, P. Castany, T. Gloriant, Acta Mater. 61 (2013) 511.

[7] H.Y. Kim, H. Satoru, J.I. Kim, H. Hosoda, S. Miyazaki, Mater. Trans. 45 (2004) 2443.

[8] Y. Fukui, T. Inamura, H. Hosoda, K. Wakashima, S. Miyazaki, Mater. Trans. 45 (2004) 1077.

[9] Y.L. Hao, Z.B. Zhang, S.J. Li, R. Yang, Acta Mater. 60 (2012) 2169.

[10] M. Tahara, H.Y. Kim, H. Hosoda, T.-h. Nam, S. Miyazaki, Mater. Sci. Eng. A 527 (2010) 6844.

[11] M. Besse, P. Castany, T. Gloriant, Acta Mater. 59 (2011) 5982.

[12] A. Ramarolahy, P. Castany, F. Prima, P. Laheurte, I. Péron, T. Gloriant, J. Mech. Behav. Biomed. Mater. 9 (2012) 83. 
[13] A. Nyayadhish, B.C. Maji, M. Krishnan., ICOMAT-08 Conf. Proc., in: G.B. Olson, D.S. Lieberman, A. Saxena (Eds.), TMS, 2009 pp. 493-497.

[14] E. Takahashi, T. Sakurai, S. Watanabe, N. Masahashi, S. Hanada, Mater. Trans. 43 (2002) 2978.

[15] Y. Ohmori, T. Ogo, K. Nakai, S. Kobayashi, Mater. Sci. Eng. A 312 (2001) 182.

[16] D.L. Moffat, D.C. Larbalestier, Metal. Trans. A 19 (1988) 1677.

[17] S. Nag, R. Banerjee, R. Srinivasan, J.Y. Hwang, M. Harper, H.L. Fraser, Acta Mater. 57 (2009) 2136.

[18] T. Gloriant, G. Texier, F. Sun, I. Thibon, F. Prima, J.L. Soubeyroux, Scripta Mater. 58 (2008) 271.

[19] K. Masumoto, Y. Horiuchi, T. Inamura, H. Hosoda, K. Wakashima, H.Y. Kim, S. Miyazaki, Mater. Sci. Eng. A 438-440 (2006) 835.

[20] H.S. Kim, W.Y. Kim, S.H. Lim, Scripta Mater. 54 (2006) 887. 

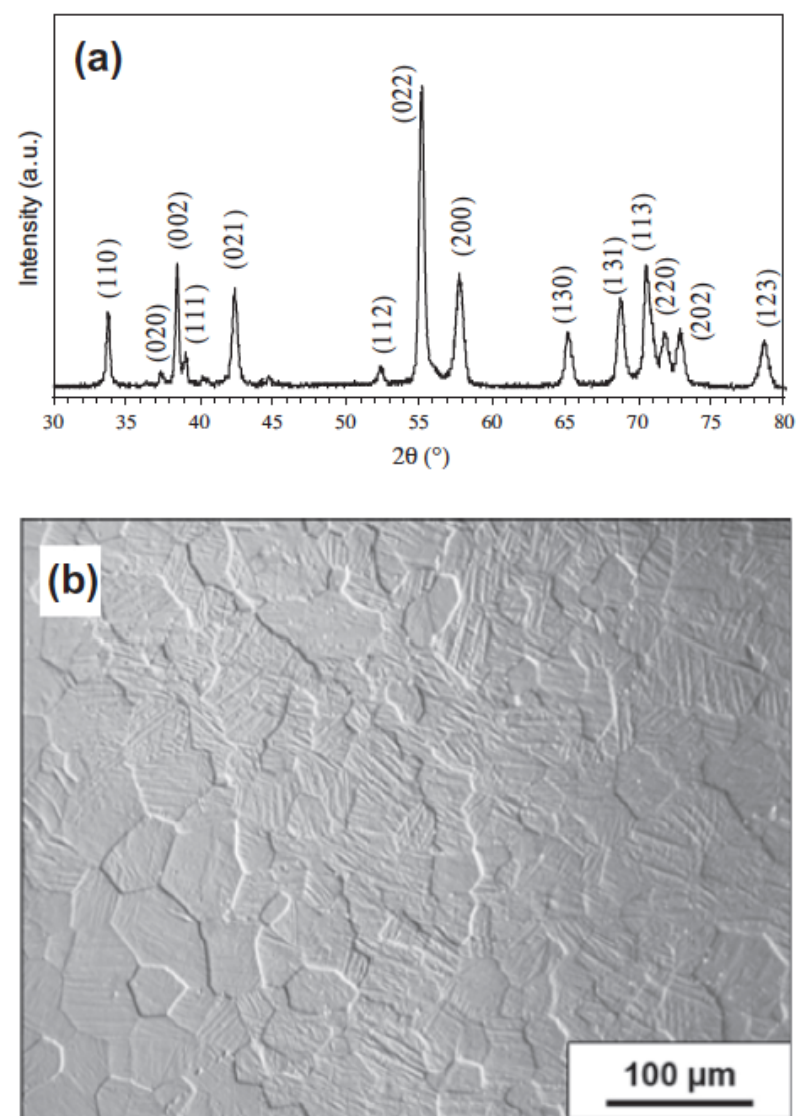

Fig. 1. X-ray diffraction profile (a) and optical micrograph (b) of the solution-treated and quenched Ti-24Nb-0.5Si alloy.

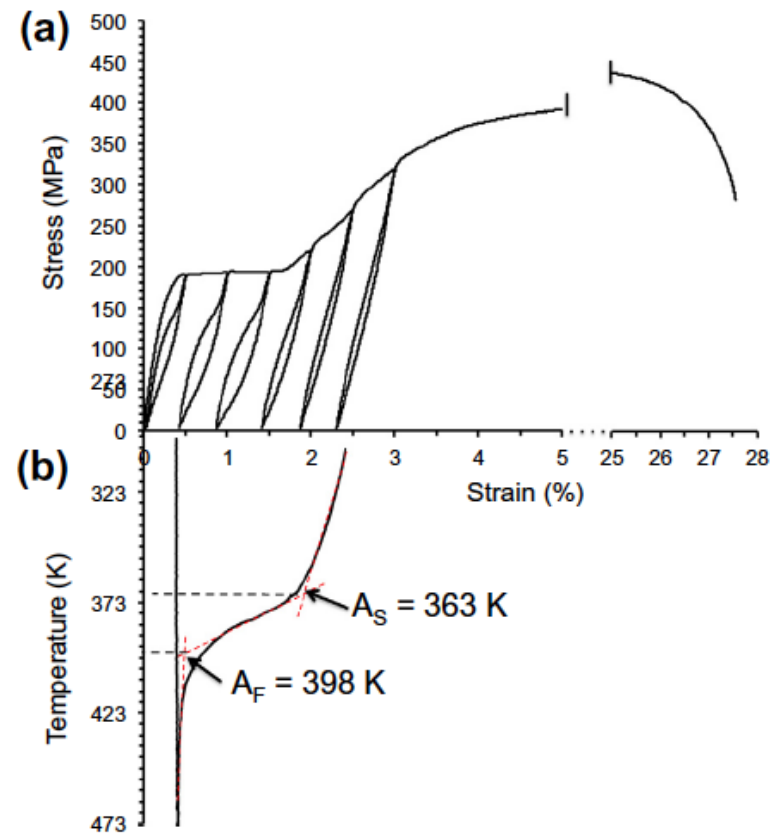

Fig. 2. Stress-strain tensile curve (a) obtained from the solution-treated Ti-24Nb-0.5Si alloy and DMA strain-temperature curve (b) obtained from the deformed (up to 3\% strain) solutiontreated $\mathrm{Ti}-24 \mathrm{Nb}-0.5 \mathrm{Si}$ alloy. 

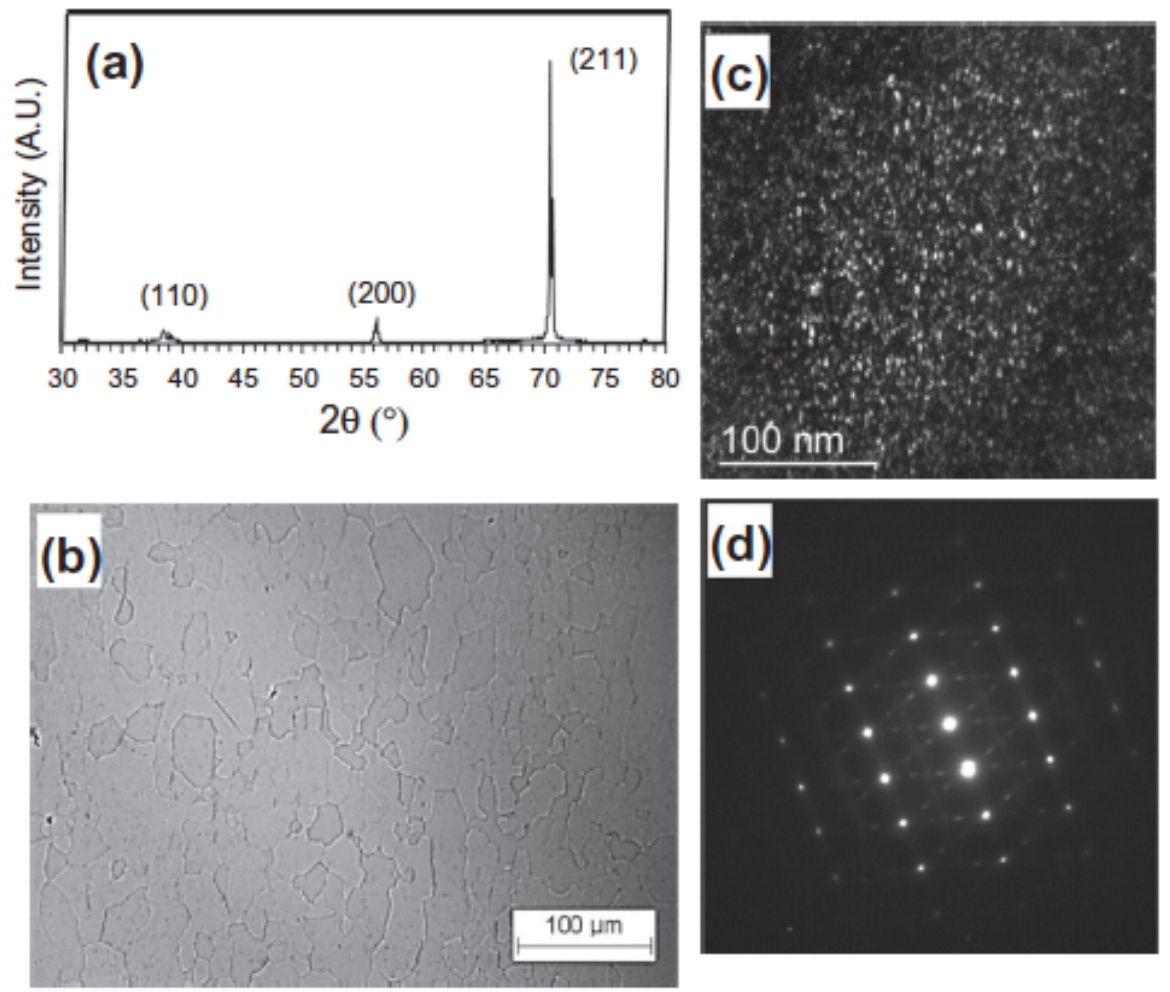

Fig. 3. X-ray diffraction profile (a) and optical micrograph (b) of the $\beta$-phase microstructure of the Ti-24Nb-0.5Si alloy after being heated up to 473K. Dark field TEM image (c) and corresponding selected area diffraction pattern (d) ([ $\left[\begin{array}{lll}1 & 1 & 3\end{array}\right]_{\beta}$ zone axis) showing the $\omega_{\text {iso }}$ nanoprecipitates.

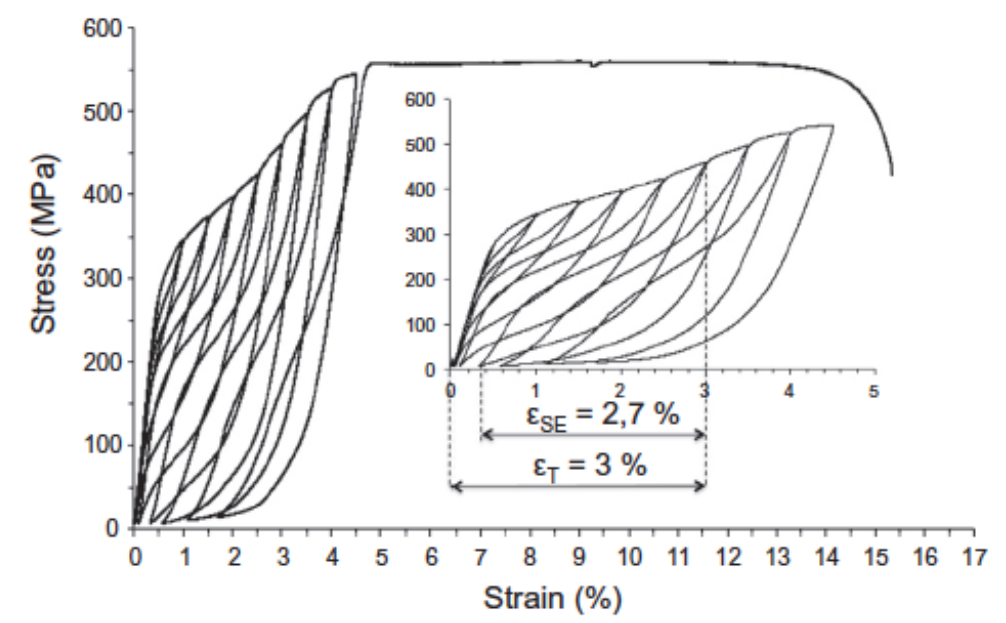

Fig. 4. Stress/strain curve showing the superelastic behavior of the Ti-24Nb-0.5Si alloy after being heated up to $473 \mathrm{~K}$. 